\title{
LAS DIPUTACIONES PROVINCIALES Y SU FUTURO INCIERTO
}

\author{
ENRIQUE LINDE PANIAGUA \\ Catedrático Emérito de Derecho Administrativo \\ UNED
}

\begin{abstract}
SUMARIO
I. Introducción. II. Las provincias son instituciones constitucionales que no son indispensables para el régimen democrático. III. La supresión o sustitución de las diputaciones provinciales por otras instituciones no exige la reforma constitucional. La provincia como entidad local ha sufrido una mutación. IV. La organización administrativa debe subordinarse a las necesidades de los ciudadanos. V. Las competencias que ejercen las diputaciones provinciales: ¿son imprescindibles? La Ley 27/2013. VI. El futuro de las diputaciones provinciales no debiera trazarse de manera aislada sino teniendo en cuenta la estructura territorial del Estado de las Autonomías. Una propuesta de lege ferenda
\end{abstract}

\section{INTRODUCCIÓN}

Las diputaciones provinciales están en el ojo del huracán político y jurídico desde hace muchos años ${ }^{1}$. Algunos partidos políticos han incluido en sus programas electorales la supresión de las mismas, mientras que otros las siguen considerando estructuras administrativas necesarias en el Estado de las Autonomías. Los que postulan la supresión de las diputaciones provinciales lo hacen por considerar, como uno de sus argumentos principales, que dicha supresión supondría un ahorro considerable de recursos ${ }^{2}$, que calculan en algunos miles de millones de euros al año, mientras que los que defienden su existencia las consideran necesarias para atender a los miles de pequeños municipios españoles que son incapaces de satisfacer, por si mismos, las

1 Lo cierto es que desde la promulgación de la Constitución se aprecian tensiones a propósito de las diputaciones provinciales, al efecto puede verse el lúcido opúsculo de M. CLAVERO ARÉVALO, Igualdad, uniformidad y variedad en el tratamiento constitucional de las autonomías, Universidad de Granada, 1979.

2 Ver en este sentido M. SÁNCHEZ MORÓN, «¿Deben suprimirse las diputaciones provinciales?», El Cronista del Estado Social y Democrático de Derecho», nº 65, 2017. 
necesidades más elementales de sus vecinos. Los citados argumentos, a mi juicio, tienen escasa consistencia, tanto para fundamentar la supresión como para postular la existencia de las diputaciones provinciales, pues la reducción del gasto no puede contemplarse de un modo aislado, sin considerar aspectos sustanciales como la función que desempeñan las diputaciones desde la perspectiva de las necesidades de los ciudadanos y, por otra parte, la supresión de las diputaciones provinciales no tiene porqué suponer menoscabo de los servicios que en la actualidad prestan, que podrían ser desempeñados por otras instituciones con igual o mayor eficacia y eficiencia.

El debate político sobre el mantenimiento, la reforma o la supresión de las diputaciones provinciales pone de manifiesto posiciones de poder. Los partidos políticos que controlan las diputaciones provinciales en la actualidad, y desde el inicio de la etapa democrática, postulan su mantenimiento o reforma, mientras que los partidos políticos emergentes, que no controlan ninguna de las diputaciones provinciales españolas, se muestran, con mayor o menor claridad, contrarios a las mismas.

Aunque no dejaría de tener interés un análisis de los debates políticos que han tenido y están teniendo lugar sobre las diputaciones provinciales, más allá de los argumentos antes señalados, este trabajo no los abordará y se centrará en algunos de los problemas que suscitan dichas organizaciones en la actualidad, en particular su encaje en nuestro sistema político-administrativo.

Las diputaciones provinciales tuvieron un papel relevante en el tránsito desde la Dictadura al Estado de las Autonomías, pues la Constitución les otorgó, en sus artículos 143.2 y 151.1 , la iniciativa en el proceso autonómico ${ }^{3}$. Al margen de esta función coyuntural ya extinguida, la Constitución, en su artículo 141 , encomienda a las diputaciones provinciales el gobierno y la administración autónoma de las provincias como entidades locales a las que dota de personalidad jurídica propia (arts. 137, 141.1 y 143.1 C.). Por otra parte, las provincias son divisiones territoriales para el cumplimiento de las actividades del Estado (art. 141.1 C.). Y, en tercer lugar, las provincias son también circunscripciones electorales (art. 68.2 y 69.2 y 3 C.) ${ }^{4}$.

El constituyente español cuando reguló las tres facetas de la provincia actualmente vigentes reflejó el estado de cosas existentes en España en 1978, con la única variante de proclamar la autonomía de los entes locales, pero sin tener en consideración el nuevo Estado de las Autonomías que la Constitución alumbraba. Se podría considerar que el constituyente consagró una anomalía porque la provincia desde sus

3 Sobre los sistemas de creación de Comunidades Autónomas previstos en la Constitución de 1978 puede verse mi trabajo: «Procedimientos de creación de Comunidades Autónomas», en Documentación Administrativa, $\mathrm{n}^{\circ} 182,1979$, pp. 288 a 366.

4 Las provincias son además mencionadas en el artículo 158.2 CE que prevé la participación de las provincias en el Fondo de Compensación Interterritorial, desarrollado por la Ley 22/2001, de 27 de diciembre, reguladora de los Fondos de Compensación Interterritorial, ver en particular su artículo 9. También el Título III «Recursos de las provincias», artículos 131 a 149, y siguientes del Real Decreto Legislativo 2/2004, de 5 de marzo, por el que se aprueba el texto refundido de la Ley Reguladora de las Haciendas Locales. 
orígenes, y pese a los numerosos cambios que sufre desde la Constitución de Cádiz ${ }^{5}$, ha sido en sus diferentes versiones una institución que representa una concepción centralista del Estado que contrasta con la concepción descentralizada que la Constitución de 1978 instaura. De manera que uno de los temas que deberemos abordar es el encaje de las provincias y las diputaciones provinciales en el marco del Estado de las Autonomías, así como, para el caso de su supresión, dónde deben residenciarse las competencias que las diputaciones provinciales realizan en la actualidad.

\section{LAS PROVINCIAS SON INSTITUCIONES CONSTITUCIONALES QUE NO SON INDISPENSABLES PARA EL RÉGIMEN DEMOCRÁTICO}

La primera cuestión que nos planteamos es la de si diputación provincial y provincia, en sus distintas versiones, están indisolublemente unidas en la Constitución, o si, por el contrario, la supresión de una de ellas no supone necesariamente la supresión de la otra u otras.

A la luz de lo dispuesto en los artículos de la Constitución que mencioné más atrás se puede llegar a la conclusión, con la jurisprudencia del Tribunal Constitucional $^{6}$, de que «la provincia», en sus diferentes facetas, puede calificarse de institución constitucional, garantizada por la Constitución, cuya supresión o modificación solo podría llevarse a cabo mediante una reforma constitucional, por el procedimiento ordinario del artículo 167 del texto constitucional, al no afectar a las materias a que se hace referencia en el artículo 168 del texto fundamental.

Sin embargo, la afirmación anterior debe relativizarse por varias razones. Así, la garantía institucional de la provincia no puede calificarse de institución indispensable para la existencia de un régimen constitucional democrático. Esto es, a diferencia de la exigencia de que existan los poderes ejecutivo, legislativo y judicial, en las formas actuales o en otras, para la existencia de un régimen constitucional-democrático, las provincias, las diputaciones e incluso las comunidades autónomas son opciones organizativas de las que podría prescindirse sin menoscabo de la democracia. De manera que las provincias y las diputaciones provinciales podrían suprimirse sin que dicha supresión pusiera en cuestión el sistema democrático. Versiones semejantes a la provincia existen en la mayoría de los Estados de la Unión Europea que, desde la Ilustración, han evolucionado en sus modelos organizativos

5 La bibliografía sobre la provincia es muy abundante ver por todos R. PARADA VÁZQUEZ Y M. BACIGALUPO SAGGESE, "Artículo 141. La provincia y otras entidades supranacionales», O. ALZAGA VILLAAMIL (Dir), Comentarios a la Constitución Española de 1978, Tomo X, pág. 517 y ss.

6 Ver la sentencia 32/1981, de 28 de julio sobre la garantía institucional de la provincia, que sin embargo no se caracteriza por su claridad, justifica de manera un tanto sorprendente la supresión de las provincias como entidad local en las comunidades autónomas uniprovinciales como una sublimación de la provincia con argumentos poco consistentes. Ver también la sentencia 27/1987, de 27 de febrero, del Tribunal Constitucional, sobre coordinación de las diputaciones provinciales. 
de modo similar al español ${ }^{7}$. No obstante, la observación anterior no puede aplicarse a los municipios, instituciones de gran arraigo cuya supresión como organizaciones político-administrativas exigiría crear otras instituciones locales que afrontaran algunas de las necesidades elementales que tienen los ciudadanos. En cualquier caso no debe olvidarse que existen en el ordenamiento jurídico español otras entidades locales de segundo grado como las comarcas, $u$ otras agrupaciones de municipios, las áreas metropolitanas y las mancomunidades, así como otras entidades de ámbito territorial inferior al municipal (como caseríos, parroquias, aldeas, barrios, anteiglesias, concejos, pedanías, lugares anejos y otros análogos). Estos tipos de entes locales creados por la ley tienen por finalidad: unos la descentralización de funciones y otros la asociación entre municipios para una mayor eficacia y eficiencia en el ejercicio de sus funciones. De algún modo la proliferación de este tipo de entes locales, particularmente los asociativos, pone de manifiesto que las diputaciones provinciales han fracasado de manera estrepitosa en relación con los medianos y grandes municipios que han encontrado en los entes locales de segundo grado la solución a sus insuficiencias más notorias. La planta local en nuestro ordenamiento jurídico es de enorme complejidad y hay que decir que las diputaciones provinciales no son sino un problema más de entre los muchos que la aquejan.

La segunda cuestión que debemos plantearnos es la de si es posible establecer una vinculación necesaria entre las tres facetas de la provincia que se configuran en el texto constitucional. Esto es, si las tres facetas de la provincia están vinculadas inexorablemente, de modo que la supresión de una traiga la necesidad ineludible de suprimir las otras o si, por el contrario, se trata de organizaciones administrativas desconectadas entre sí, es decir, si se habría utilizado el término provincia para designar tres conceptos diferentes en los que la única coincidencia que se da entre los mismos es su ámbito territorial. Pues bien, no es posible encontrar precepto constitucional o legal alguno que conduzca a la vinculación de las tres facetas de la provincia, aunque es evidente que las tres versiones responden a un mismo criterio ideológico, el del centralismo ilustrado tardío, más allá del intento de vinculación que se ha hecho de la existencia de las provincias con la dictadura franquista. De manera que la supresión, en su caso, de las provincias como entes locales no afectaría lo más mínimo a la existencia de circunscripciones electorales provinciales, ni a la conservación del ámbito provincial a los efectos de las actividades de la Administración periférica del Estado. Y en sentido contrario puede llegarse a la misma conclusión, es decir, aunque se modificaran las circunscripciones electorales provinciales, reguladas en la legislación electoral ${ }^{8}$, o en el caso de que el Estado modificara el ámbito de actuación de su Administración periférica, regulada en la

7 Entre los muchos trabajos que prestan atención al derecho comparado pueden verse los de L.I. ORTEGA ÁLVAREZ, «La Comunidad Autónoma de Madrid como área metropolitana», VV.AA. , Madrid Comunidad Autónoma Metropolitana, pp. 131 y ss.

8 Así, la LO 5/1985, de 19 de junio, del Régimen Electoral General en sus artículos 202 a 209 está dedicada a las «Disposiciones especiales para la elección de diputados provinciales» . 
actualidad en la legislación sobre régimen jurídico del sector público ${ }^{9}$, las provincias podrían subsistir como entes locales. Y esto, fundamentalmente, porque la versión de la provincia como entidad local es tan artificiosa como las otras dos versiones de la provincia, y escasamente arraigada en España. Difícilmente podría ser de otro modo tratándose la provincia de una entidad local que se integra por una suerte de agrupación de municipios, como establece el artículo 141.1 de la Constitución, cuyas funciones, por lo general, no son percibidas directamente por los ciudadanos, ya que los interlocutores y destinatarios directos de sus actividades son los ayuntamientos pequeños y medianos, salvo alguna excepción.

El pretendido arraigo entre los españoles de la provincia como ente local ha sido una ensoñación ilustrada de los ideólogos tardíos del centralismo. Los españoles, de acuerdo con las encuestas más fiables sienten arraigo, en primer lugar, con sus municipios, con sus pueblos y, en segundo lugar, con sus regiones. Incluso se aprecia, en no pocos ciudadanos españoles, una cierta aversión a su vinculación a la provincia, especialmente cuando, como sucede por lo general, la denominación de la provincia coincide con la denominación de la capital de la misma con la que solo se suelen sentir identificados los vecinos de la misma.

Aunque no sea objeto de este trabajo la consideración de la provincia como circunscripción electoral, en los términos previstos en la Constitución y en la Ley orgánica del Régimen Electoral General, puede también ponerse en tela de juicio por ser causa de la desigualdad del valor del voto de los españoles. Y, por otra parte, la división provincial, en lo relativo a la prestación de actividades por el Estado en el territorio nacional, no deja de ser una muestra más de lo difícil que le resulta a la Administración General del Estado adaptarse a los nuevos retos o, si se prefiere, a las dificultades para prescindir de un modelo de organización escasamente especializado y claramente ineficaz e ineficiente. Pero, como decía, éstos no son temas que corresponda analizar en este lugar.

En tercer lugar debemos plantearnos si en el Estado de las Autonomías la Administración General del Estado y la Administración local deben adaptarse a las Comunidades Autónomas o si unas y otras administraciones deben o pueden responder a principios organizativos diferentes. Este es un asunto que dejare para el final.

\section{LA SUPRESIÓN O SUSTITUCIÓN DE LAS DIPUTACIONES PROVINCIALES POR OTRAS INSTITUCIONES NO EXIGE LA REFORMA CONSTITUCIONAL. LA PROVINCIA COMO ENTIDAD LOCAL HA SUFRIDO UNA MUTACIÓN}

Antes concluimos que la «provincia» es una institución cuya supresión exige la reforma constitucional. Esta conclusión, sin embargo, no puede trasladarse sin

9 Al efecto puede verse la Ley 40/2015, de 1 de octubre, de régimen jurídico del sector público 
más a la provincia como entidad local o a las diputaciones provinciales. En el artículo 141.2 de la Constitución se establecen con claridad meridiana dos posibilidades, en lo que concierne al gobierno y la administración autónoma de la provincia como ente local: que se lleve a cabo mediante diputaciones; o que se lleve a cabo mediante otras corporaciones de carácter representativo. Además, el apartado 3 del mismo artículo 141 establece que se podrán crear agrupaciones de municipios diferentes de la provincia. Por otra parte, las islas de los archipiélagos tendrán su propia administración en forma de cabildos y consejos. Y, finalmente, las diputaciones forales vascas se rigen por sus propias normas. Es decir, (dejando al margen las comunidades autónomas uniprovinciales), la diputación provincial de régimen común no es una institución general sino que tan solo afecta a 38 de las 50 provincias españolas, pues en las comunidades autónomas uniprovinciales la diputación ha sido suprimida (Asturias, Cantabria, Madrid, Navarra, Murcia, Rioja), las provincias canarias (Tenerife y Las Palmas) y la balear se organizan de manera singular y las 3 provincias vascongadas tienen, igualmente, un régimen singular.

Así, las diputaciones provinciales no serían sino una modalidad de gobierno de la provincia como entidad local que puede ser elegida por el legislador estatal. Pero, en caso alguno puede decirse que las diputaciones sean el modo constitucional necesario de gobernar las provincias como entes locales. En este sentido la Ley 27/2013 de racionalización y sostenibilidad de la Administración local, que modifica el artículo 26 de la Ley 7/1985, de las Bases del Régimen Local, en su apartado 2, al regular las competencias de las diputaciones provinciales se refiere a «diputación provincial o entidad equivalente», lo que podría suponer una puerta abierta a otros modos de gestión de las provincias, salvo que se este haciendo referencia a las diputaciones forales vascas, a las que dedica las disposiciones adicionales segunda y octava, o a la Comunidad Foral de Navarra a la que se dedica una disposición adicional tercera. Pero al margen de que se puede especular sobre la mención a «entidad equivalente» del apartado 2 del artículo 26 de la Ley 7/1985, la dicción del apartado 2 del artículo 141 de la Constitución no ofrece dudas, el gobierno y la administración autónoma de las provincias puede encomendarse a las diputaciones provinciales o a otras «corporaciones de carácter representativo». La misma referencia a entidades equivalentes a o corporaciones de carácter representativo se hace en los artículos 36 y 38 de la mencionada Ley de bases que regulan las competencias propias de las diputaciones provinciales que afectan de manera prácticamente exclusiva a los municipios de menos de 20.000 habitantes.

El constituyente fue especialmente precavido al no vincular de modo necesario la provincia como ente local a las diputaciones, así como previendo, en su caso, la convivencia de las provincias con otras agrupaciones de municipios diferentes a las mismas que pudieran crearse en los límites provinciales, o más allá de dichos límites, aunque no puede deducirse explícitamente de dicho precepto (artículo 142. 2 y 3 de la C.) que dichas agrupaciones puedan permitir la liquidación de las provincias. 
De lo dicho, y particularmente del apartado 2 del artículo 141, se deduce que el constituyente no dejó el tema relativo al gobierno de las provincias cerrado como muchos pretenderían. Existen varias posibilidades abiertas permanentemente para el legislador, aunque el legislador estatal se haya decantado por las diputaciones provinciales en las 38 provincias de régimen común. Así, el legislador podría crear corporaciones diferentes a las diputaciones para administrar la provincia como ente local y, además, puede crear entes locales diferentes a las provincias y, por tanto, la posibilidad de que éstas sean gestionadas por otras organizaciones político-administrativas a las que la Constitución denomina «corporaciones» diferentes a las diputaciones, o que las corporaciones que gobiernen las provincias como ente local convivan con agrupaciones de municipios diferentes de las provincias.

Resulta necesario entrar a valorar el significado que debe darse al término corporación en el citado artículo de la Constitución. A mi juicio procedería una interpretación que pudiera alejarse del concepto de corporación que no fuera la mera constancia de un modo de organización que se refiere a los entes locales. El constituyente estaría exigiendo que la corporación sea democrática, es decir, que sea democrática la organización administrativa que administre tanto la provincia como las posibles agrupaciones diferentes a la provincia; pero no necesariamente que las organizaciones que se creen sean semejantes a las diputaciones o a los municipios.

El constituyente no podía concebir el desarrollo del Estado de las Autonomías y, por tanto, recurrió a un modelo organizativo conocido como el de «corporación», pero la finalidad del constituyente no fue otra que de concebir que la organización que rija las provincias, u otras agrupaciones de municipios, sea democrática. $\mathrm{Y}$ en esa medida las provincias u otras agrupaciones podrían ser regidas por las comunidades autónomas.

La circunstancia de que en las comunidades autónomas uniprovinciales se hayan suprimido las diputaciones provinciales ${ }^{10}$, cuyas funciones son desempeñadas por las propias comunidades autónomas, pone en crisis el que pudiera ser un argumento capital para los defensores de las diputaciones provinciales, que pudiera sustentarse en el propio artículo 141: el de que la Constitución exigiría que la organización que gobierne y administre de manera autónoma las provincias tenga un origen en la agrupación de los municipios que la integran. Así, la circunstancia de que en las comunidades autónomas uniprovinciales las funciones de las diputaciones provinciales hayan sido asumidas por las propias comunidades autónomas exige preguntarse si, además, en esas comunidades se han suprimido las provincias, sin la correspondiente reforma constitucional, o si bien sobrevive la provincia como ente local, cuyo gobierno y administración autónoma corresponde a la comunidad

10 La supresión se postuló por el Informe dela Comisión de Expertos sobre Autonomías (CEC, Mayo, 1981), que se convirtió en el artículo 9 de la Ley 12/1983, de 14 de octubre, del Proceso Autonómico. 
autónoma, mientras que la provincia en sus vertientes de circunscripción electoral y como división territorial para el cumplimiento de las actividades del Estado siguen estando vigentes en las comunidades autónomas uniprovinciales.

La argumentación utilizada para justificar la supresión de las diputaciones provinciales ha sido que las competencias de éstas y las de las comunidades autónomas uniprovinciales se iban a solapar, lo que sin duda es cierto. Pero este mismo argumento puede servir para justificar la supresión de las diputaciones en comunidades autónomas pluriprovinciales ${ }^{11}$, con la particularidad de que en éstas el solapamiento de sus competencias se producirá con las de varias diputaciones provinciales. Dicho solapamiento se estaría produciendo en la medida en que las comunidades autónomas pluriprovinciales han creado, todas ellas, servicios provinciales para el ejercicio de sus funciones.

El carácter no necesario de las diputaciones provinciales para el gobierno y administración autónoma de las provincias encuentra su fundamento más consistente en la circunstancia de que en las comunidades autónomas uniprovinciales se haya prescindido de la institución, sin que la Constitución hubiera previsto esta circunstancia de manera explícita o implícita. Ahora bien: ¿puede entenderse que estamos ante la aplicación de la alternativa a que se refiere el apartado 2 del artículo 141 de la Constitución? Es decir, podría entenderse que las comunidades autónomas uniprovinciales serían la «corporación de carácter representativo» a que se refiere el apartado 2 del artículo 141. Lo cierto es que la posibilidad más acorde al mencionado artículo constitucional es admitir la hipótesis enunciada pues la Constitución no prevé ninguna otra alternativa para dar encaje a dicha supresión. En este sentido se pronunció el apartado 2 del artículo 9 de la Ley 12/1983, de 14 de octubre, del Proceso Autonómico ${ }^{12}$, que fue considerado conforme a la Constitución por el Tribunal Constitucional en su sentencia 76/1983, de 5 de agosto, que tuvo por objeto la constitucionalidad de la mencionada ley ${ }^{13}$.

De ser acertada la conclusión anterior pueden deducirse de la misma otras conclusiones. Debe descartarse que cuando la Constitución se refiere a «corporaciones de carácter representativo» esté exigiendo que dichas corporaciones se integren por representantes de los municipios que agrupa, sino que, en la versión alternativa que ha esbozado la Constitución, permite que el carácter representativo se refiera a los

11 Las CCAA pluriprovinciales no son ni homogéneas en el número de provincias que comprenden, ni en las dimensiones de los territorios que comprenden, ni en el número de municipios, ni en la población. Así, existen CCAA que constan de 2 provincias (Extremadura, Canarias), de 3 provincias (Aragón, Comunidad Valenciana y País Vasco), de 4 provincias (Cataluña y Galicia), de 5 provincias (Castilla-la Mancha) y de 8 provincias (Andalucía y Castilla y León)

12 Vid ampliamente en J.L. DE LA VALLINA VELARDE, «La Administración local en el Principado de Asturias: relaciones con la Comunidad Autónoma», Revista de Estudios de la Administración Local, $\mathrm{n}^{\circ} 291$, 2003, pp. 1167 y ss. En este artículo puede verse la polémica sobre el artículo 9.2 de la Ley 12/1983.

13 El Informe de la Comisión de Expertos sobre autonomías (CEC, mayo de 1981) postulaba que «En las comunidades autónomas uniprovinciales la diputación se integrará en la organización política de aquélla, y sus servicios administrativos seguirán siendo la base de la nueva administración regional», pág. 103. 
ciudadanos de la provincia y, en esa medida, tan representativos de los ciudadanos son los gobiernos de las comunidades autónomas como las diputaciones, pues en ambos casos la elección de órganos de gobierno de unas y otras son el resultado de elecciones en segundo grado. En este punto hay que señalar que la Carta Europea de Autonomía Local ${ }^{14}$ vincula el derecho a la autonomía local en su artículo 3 apartado 2, a que sea ejercido por «Asambleas o Consejos integrados por miembros elegidos por sufragio libre, secreto, igual, directo, universal». Estos requisitos no concurren en la elección de los miembros de las diputaciones provinciales que son todos ellos concejales elegidos en las elecciones municipales y designados por sus respectivos partidos políticos ${ }^{15}$, por lo que la mencionada Carta no ampararía las diputaciones provinciales en su versión actual ${ }^{16}$.

De manera que podríamos concluir que de acuerdo con la Constitución es posible prescindir de las diputaciones provinciales para el gobierno y administración de los entes locales provinciales ${ }^{17}$. La Ley 12/1983, del Proceso autonómico, sin embargo, no se pronuncia sobre las consecuencias, para la provincia como ente local, de la asunción por las comunidades autónomas de las competencias de las diputaciones provinciales, y tampoco se hace referencia a esta cuestión en los estatutos de autonomía de las comunidades autónomas uniprovinciales. No obstante, no cabe duda de que se ha operado una mutación del concepto de provincia como ente local que por virtud de lo dispuesto en la legislación de régimen local podría suprimirse sin modificar la Constitución.

\section{LAS COMPETENCIAS QUE EJERCEN LAS DIPUTACIONES PROVINCIALES ¿SON IMPRESCINDIBLES? LA LEY 27/2013 DE RACIONALIZACIÓN Y SOSTENIBILIDAD DE LA ADMINISTRACIÓN LOCAL}

Las diputaciones provinciales tienen su principal justificación funcional en la necesidad de prestar una serie de servicios de los que son destinatarios principales, directamente, los pequeños municipios españoles. En España existen 8.115

14 Hecha en Estrasburgo el 15 de octubre de 1985, que fue publicada en el BOE $\mathrm{n}^{\circ} 47$, de 24 de febrero de 1989. El requisito de que los miembros de las diputaciones provinciales sean elegidos directamente no ha sido advertido por algunos autores que han analizado la mencionada Carta, ver al respecto I. LASAGABASTER HERRARTE, La Carta Europea de la Autonomía Local, Iustel, pág. 39 y ss.

15 Ver los artículos 202 y siguientes de la LO 5/1985, de 19 de junio, del Régimen Electoral General.

16 No siempre ha sido así, La Ley electoral del Congreso de 26 de junio de1890 en su artículo 1 adicional disponía la aplicación de los artículo 1 y 2 de la misma, que establece la capacidad para ser electores a las elecciones a diputados provinciales, ver V. SANTAMARÍA DE PAREDES, Curso de Derecho Administra-

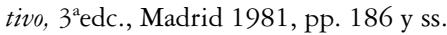

17 No obstante, se puede coincidir con J.L. DE LA VALLINA VELARDE, ob. cit. pág. 1173, que la solución adoptada es un tanto forzada, aunque atribuye a hechos imponderables dicha solución; la imposibilidad de prever en 1978 el desarrollo que iba a darse a las CCAA. 
municipios de los que solo 392 tienen más de 20.000 habitantes, es decir, el 95 por ciento de los municipios españoles tiene menos de 20.000 habitantes ${ }^{18}$, umbral al que la Ley 27/2013 otorga gran relevancia en lo relativo a las competencias que deben ejercer las diputaciones provinciales.

Pero la posible reforma de la arquitectura de la organización territorial no puede partir, como si de una cuestión incontrovertible se tratara, de la existencia de esos miles de municipios incapaces de afrontar mínimamente las necesidades elementales de sus vecinos: aquellas que se han identificado a lo largo de la historia con competencias municipales necesarias para la vida ordinaria. Y esto porque a los municipios hay que trasladar igualmente los principios por los que se rige toda organización territorial que tiene como finalidad satisfacer las necesidades de los ciudadanos que pretende organizar. En España el extraordinario número de municipios se debe a que, a salvo de las excepciones que se advierten en algunas comunidades autónomas, los municipios históricamente se han construido haciéndolos corresponder a la existencia de cualquiera agrupación urbana que existiera en el territorio español. Cuando en un mismo término municipal se ha desarrollado una agrupación urbana, alejada de la agrupación urbana matriz, los vecinos de la nueva agrupación urbana han solicitado insistentemente la segregación del municipio originario y han conseguido crear un nuevo municipio. Los ejemplos son numerosos, por el contrario son prácticamente inexistentes en las últimas décadas los municipios que solicitan agruparse con otro u otros municipios con objeto de poder satisfacer de manera más eficaz y eficiente las necesidades de sus habitantes. Y en este sentido la Ley 27/2013 lejos de disuadir parece estimular la segregación de partes de los municipios existentes en la actualidad al fijar como umbral necesario para solicitar la segregación que el nuevo municipio tenga más de 5.000 habitantes.

El futuro de las diputaciones provinciales depende directamente de las disfunciones municipales que se aprecian en España. Si no se concibe un nuevo tipo de municipio desvinculado de agrupación urbana, y vinculado a la finalidad de satisfacer las necesidades de los ciudadanos, serán necesarias las diputaciones o otras organizaciones que sustituyan a los municipios y ayuntamientos fallidos. La concentración de agrupaciones urbanas, que en la actualidad son municipios, que puedan afrontar las necesidades de sus vecinos, puede hacerse sin menoscabo de las singularidades de las agrupaciones urbanas que incluya. De hecho, los municipios de numerosas poblaciones españolas, particularmente los más poblados, contienen diferentes agrupaciones urbanas discontinuas. Y, viceversa, pueden existir razones de peso para que las grandes conurbaciones se integren por varios

18 Existen 1.041 municipios con menos de 100 vecinos; 2.759 municipios con entre 100 a 500 vecinos; 1.062 municipios con entre 500 a 1000 vecinos, 1.937 municipios con entre 1.000 a 5.000 vecinos; 564 municipios entre 5.000 a 10.000 vecinos; 355 municipios entre 10.000 a 20.000 vecinos; 83 municipios entre 50.000 y 100.000 vecinos; 33 municipios entre 100.000 y 200.000 vecinos; 4 municipios entre 500.000 a 1.000 .000 vecinos y 2 municipios de más de 1 millón de vecinos. 
municipios que pueden, no obstante, crear otros entes locales relacionales como las áreas metropolitanas con objeto de afrontar la solución eficiente de problemas que a todos les afectan y que deben afrontarse de manera asociada.

Pudiera parecer que el que se plantea es un problema que poco tiene que ver con el tema principal que nos ocupa, ya que se integren los municipios actuales en otros municipios que permitan afrontar de manera efectiva y eficiente las competencias municipales, o que no lo hagan, podría entenderse que son alternativas independientes de considerar que las diputaciones sean o no necesarias. Sin embargo, no pueden separarse ambos temas. Tras 40 años de vigencia de la Constitución ningún gobierno de la nación ha afrontado el problema de la planta municipal, ni una seria reforma de la Administración española. Y la causa es evidente, los intereses políticos, en particular los electorales, se verían afectados a corto plazo, gravemente, por el partido político que emprendiera una reforma de la planta municipal, sin el apoyo unánime de los demás partidos políticos. La falta de visión de Estado, que caracteriza a los partidos políticos españoles, garantiza que los problemas que tenemos no se solucionen. En esto se aprecia una diferencia notable con otros Estados miembros de la Unión, como los casos de Francia, Italia o Alemania que han llevado a cabo una reforma considerable de su estructura territorial en los últimos años.

Las diputaciones provinciales, en la actualidad, garantizarían el minifundismo municipal de que adolecemos, en la medida en que la justificación principal de su existencia es precisamente dicho minifundismo municipal. Y el legislador estatal, lejos de poner en cuestión la necesidad de las diputaciones provinciales las ha reforzado sustancialmente mediante la Ley 27/2013, de 27 de diciembre, de racionalización y sostenibilidad de la Administración Local ${ }^{19}$. De manera que resulta necesario analizar algunos aspectos sustanciales de dicha ley que ha sido impugnada ante el Tribunal Constitucional que ha declarado inconstitucionales y nulos algunos de sus preceptos ${ }^{20}$.

La Ley 27/2013 contiene un preámbulo realmente didáctico. El legislador, a salvo de lo que diremos, explica con claridad que las modificaciones incluidas en la Ley tienen por finalidad: «la adecuada aplicación de los principios de estabilidad presupuestaria, sostenibilidad financiera o eficiencia en el uso de los recursos públicos locales» ${ }^{21}$

19 Sobre esta Ley pueden consultarse, VV.AA. ¿Un nuevo gobierno local en España? La reforma de la administración local en la Ley 27/2013, Anuario del Gobierno Local, junio 2014.

20 La última de las sentencias del TC es la 54/2017, de 11 de mayo de 2017 que declara inconstitucionales y nulos los apartados 3 y 4 del artículo 104 bis, introducido por el artículo 1.28 de la Ley 27/2013 y, por otra parte, que no son inconstitucionales el artículo 36.2, a) en la redacción dada por el artículo 1.13 de la Ley 27/2013 y la disposición adicional decimoquinta de la Ley 27/2013 interpretados de acuerdo con el fundamento jurídico 2 de la sentencia 54/2017, que se remite a las sentencias del Tribunal Constitucional 111/2016, FJ 12 c) y 41/2016, FJ 13 c). Anteriormente deben tenerse en cuenta las sentencias del Tribunal Constitucional 41/2016, de 3 de marzo, 111/2016, de 9 de junio, 168/2016, de 6 de octubre, 180/2016, de 20 de octubre, 44/2017 y 45/2017, ambas de 27 de abril que declaran igualmente inconstitucionales algunos preceptos de la Ley $27 / 2013$.

21 Puede verse mi trabajo «La ley de estabilidad presupuestaria y sus repercusiones en la administración local», E. LINDE y otros, Problemas actuales de la administración local, Colex, Madrid, 2003. 
y, por otra parte, la necesaria adaptación de la legislación local a los fines de la Ley 2/2012 de Estabilidad Presupuestaria y Sostenibilidad Financiera que desarrolla el artículo 135 de la Constitución, modificada en $2011^{22}$. Y para alcanzar lo mencionados objetivos considera que es necesario hacer cumplir una serie de principios o requisitos de segundo orden: El principio de «una administración una competencia»; racionalizar la estructura organizativa de la Administración Local de acuerdo con los principios de eficiencia, estabilidad y sostenibilidad financiera; garantizar un control financiero y presupuestario más riguroso; y favorecer la iniciativa económica privada evitando intervenciones administrativas desproporcionadas. En este lugar nos interesa prestar atención al primero de los principios que incide directamente en el objeto de este trabajo.

El principio que se formula en la Ley de «una administración una competencia» pretende la simplificación del mapa competencial de las administraciones públicas. Los ciudadanos en un panorama administrativo en que se realizara dicho principio, aparentemente, saldrían beneficiados, y no debemos olvidar que el Derecho administrativo moderno debe situar en el centro de las políticas a los intereses de los ciudadanos. De acuerdo con este principio no deben producirse solapamientos en el ejercicio de competencias, por las administraciones públicas

22 La reforma del artículo 135 CE se llevó a cabo con una asombrosa rapidez, proyectada por el presidente del Gobierno, Rodríguez Zapatero, siguiendo las indicaciones de la canciller alemana Angela Merkel, del presidente de BCE Mario Draghi, e incluso del presidente de los EE.UU. Barak Obama. Hasta que se reformara dicho precepto era posible en España que los Gobiernos pudieran endeudarse sin límites, o no endeudarse. Es decir, el endeudamiento mayor o menor era una competencia plena del Gobierno y del Parlamento español. Con la reforma antes mencionada, postulada por el Partido Socialista y aprobada con el apoyo del Partido Popular, se priva al Gobierno y al Parlamento de la competencia para endeudarse, ya que la mencionada ley tiene como objetivo el déficit cero. El modo de modificación de la CE es un hecho muy grave en el sentido de que ni los Tratados de la Unión Europea ni los tratados suscritos el margen de la Unión, en particular el MEDE, obligan a que el virtuosismo conservador se lleve a la CE. Con la reforma del artículo 135 de la Constitución el Gobierno y el Parlamento se han puesto la soga en el cuello que les sigue apretando dictando leyes como la Ley orgánica 2/2012, o la que comentamos.

Es evidente que un país no puede seguir una política continuada de incremento del gasto público por encima de los ingresos tributarios y de otra índole. Dicha política llevó a la situación actual en que la deuda pública es cercana al 100\% del PIB, es decir algo más de un billón de euros, es decir 166 billones de las antiguas pesetas, lo que supone en torno a 30.000 millones de euros anuales en pago de intereses de la deuda. Insoportable. En aquellas fechas en una viñeta publicada en un periódico español se ve un padre y su hijo en que el padre contemplando los datos de la deuda del estado, de las comunidades autónomas y de las administraciones locales le dice al hijo. «Algún día todo esto será tuyo». La deuda pública es una herencia envenenada para nosotros y para generaciones futuras. Gastamos lo que no tenemos y decimos a los futuros ciudadanos que paguen nuestras deudas o pretendemos que nuestros deudores nos perdonen dichas deudas. Pero en este caso los ciudadanos no pueden renunciar a la herencia, como sucede en la vida privada.

Pero, si es rechazable incrementar de modo constante la deuda pública no debe olvidarse que en 2007 la deuda pública española estaba en torno al 35\% del PIB, una de las más bajas de la Unión Europea y que los dos gobiernos PSOE y PP han multiplicado por dos dicha deuda, en más de 600.000 millones de euros en poco más de 6 años, hasta alcanzar el billón de euros, es decir, la friolera de unos 100.000 millones de euros por año, en un país en que la recaudación anual de impuestos directos no superaba en los años centrales de la crisis los 146.000 millones de euros, y en que la presión fiscal estaba en torno al 35\% del PIB. Si duda era necesario afrontar tanto el crecimiento del déficit público como la consecuencia de este, la deuda pública, dotando al Gobierno de instrumentos eficaces para ello. 
pero, además, pretende evitar las que llama situaciones de concurrencia competencial, esto es: la duplicidad de prestación de servicios; que los ayuntamientos presten servicios sin habilitación legal; que presten servicios que no le hayan sido delegados; o que no cuenten con los recursos adecuados para ello.

La Ley se refiere en todo caso a competencias y no a materias. Una materia, por ejemplo la sanidad, puede estar integrada por varias competencias, y esta circunstancia es una constante, pues lo excepcional es que una materia no se integre por varias competencias ejercidas por varias Administraciones públicas. Por ejemplo, siguiendo con la materia sanitaria el Estado tiene competencias normativas y las comunidades autónomas tienen competencias normativas de desarrollo y ejecutivas. De manera que en nuestra Constitución no es posible «una administración una materia» mientras que si es posible la aplicación del principio «una administración una competencia». El solapamiento de competencias no solo produce colisiones de competencias, que debieran evitarse, sino que son sumamente perjudiciales para los ciudadanos, salvo en algunas materias, como por ejemplo en materia de subvenciones, en que el solapamiento puede ser conveniente, siempre que exista una razonable coordinación de las distintas administraciones.

Una de las finalidades principales de la Ley 27/2013, que afecta a este trabajo, es limitar las competencias de las administraciones locales modificando la concepción misma de su sistema de competencias: de manera que el principio general que realmente se establece en la Ley 27/2013 consiste en que «las Entidades Locales no deben volver a asumir competencias que no les atribuya la ley y para las que no cuenten con financiación». Es cierto, como dice el Preámbulo de la Ley 27/2013, que los Ayuntamientos prestaban hasta la entrada en vigor de dicha ley servicios sin título competencial específico, si por ello se entiende el desempeño de servicios que no están referidos en la legislación de régimen local. Sin embargo, la Ley de Bases de Régimen Local se puede interpretar en este sentido ${ }^{23}$. Y, aunque con criterios más restrictivos, la Ley 27/2013 también permite que los municipios puedan prestar servicios sin título competencial propio, aunque la Ley 27/2013 exige que para ampliar los títulos competenciales que figuran en la misma se cuente con los recursos financieros adecuados y que no se incurra en ejecución simultánea con otra administración pública.

23 Esta amplificación de las competencias de los municipios se vio corroborada por una interpretación amplia de lo que debe entenderse como «círculo de intereses», llevada a cabo por la doctrina y por la práctica de los entes locales. Se pueden poner numerosos ejemplos de ejercicio de competencias en que resulta difícil identificar que puedan considerarse dentro del círculo de intereses de los municipios. Por ejemplo, las competencias en materia de «cooperación internacional», por no citar más que una de ellas. Todos hemos visto imágenes o noticias de alcaldes viajando a países muy alejados del nuestro inaugurando escuelas, ambulatorios, lugares de ocio, donándoles bienes muebles de la más variada naturaleza, y un largo etcétera de asuntos. También hemos visto como se distraían los fondos de la cooperación internacional por los encargados de canalizarla, que realmente se dedicaban a adquirir viviendas y apartamentos, o a otros menesteres. Sobre la polémica sobre la caracterización de los municipios como entes naturales puede verse el trabajo de J. DOMINGUEZ-ALCAHUD Y MONGE, «Tipología de los entes locales», Organización territorial del Estado (Administración Local), Instituto de Estudios Fiscales, Madrid, 1985. 
La Ley 23/2017, por una parte, diferencia entre competencias propias y competencias delegadas y, por otra parte, asigna a los municipios competencias que deben ejercer obligatoriamente en función de su población. Así, el artículo 25 apartado 2 establece una serie de materias, 15, en que los municipios tienen competencias propias ${ }^{24}$. Las competencias propias suponen un numerus clausus que solo pueden ser ejercidas por otras administraciones públicas cuando los ayuntamientos no puedan desempeñarlas, en los casos previstos en las leyes. Además, los ayuntamientos pueden ejercer competencias por delegación del Estado o de las comunidades autónomas. Es fácil concluir que solo los grandes municipios en población están en disposición de ejercer todas las competencias propias, así como ejercer por delegación competencias del Estado y de las comunidades autónomas. Por otra parte, no debe confundirse el concepto de competencias propias con materias en que los municipios tengan competencias exclusivas. Muy al contrario, todas las competencias propias de los municipios son reguladas por el Estado y las comunidades autónomas, lo que no obsta para que los municipios puedan ejercer la potestad reglamentaria. Es más, la ley debe determinar las competencias propias en cuestión, evaluando la conveniencia de la implantación de servicios locales conforme a los principios de descentralización, eficiencia, estabilidad y sostenibilidad financiera. Dicha ley debe ir acompañada, además, de una memoria económica que cumpla los requisitos del apartado 4 del artículo 25 .

Los municipios pueden ejercer competencias por delegación del Estado y de las comunidades autónomas cumpliendo los requisitos del artículo 27 de la Ley $27 / 2013$. La novedad que aporta esta ley es que en el mencionado artículo enumera las competencias que pueden delegarse y regula de manera exhaustiva el régimen jurídico de las delegaciones de competencias. La índole de las competencias susceptible de delegación indica que los municipios que pueden asumir competencias por delegación son los grandes municipios españoles.

24 Son competencias propias: a) Urbanismo, planeamiento, gestión ejecución y disciplina urbanística, protección y gestión del patrimonio histórico, promoción y gestión de la vivienda de protección pública con criterios de sostenibilidad financiera, conservación y rehabilitación de la edificación. b) Medio ambiente urbano: en particular, parques y jardines públicos, gestión de los residuos sólidos urbanos y protección contra la contaminación acústica, lumínica y atmosférica en zonas urbanas. c) Abastecimiento de agua potable a domicilio y evacuación y tratamiento de aguas residuales. d) Infraestructura viaria y otros equipamientos de su titularidad. e) Evaluación e información de situaciones de necesidad social y la atención inmediata a personas en situación o riesgo de exclusión social. f) Policía local, protección civil, prevención y extinción de incendios. g) Tráfico, estacionamiento de vehículos y movilidad. Transporte colectivo urbano. h) Información y promoción de la actividad turística de interés y ámbito local. i) Ferias, abastos, mercados, lonjas y comercio ambulante. j) Protección de la salubridad pública. k) Cementerios y actividades funerarias. 1) Promoción del deporte e instalaciones deportivas y de ocupación del tiempo libre. m) Promoción de la cultura y equipamientos culturales. n) Participar en la vigilancia de la escolaridad obligatoria y cooperar con las administraciones educativas correspondientes en la obtención de los solares necesarios para la construcción de nuevos centros docentes. La conservación, mantenimiento, vigilancia de los edificios de titularidad local destinados a centros públicos de educación infantil, de educación primaria o de educación especial. ñ) Promoción en su término municipal de la participación de los ciudadanos en el uso eficiente y sostenible de las tecnologías de la información y las comunicaciones. 
En tercer lugar los municipios pueden ejercer otras competencias, al margen de las propias y las delegadas, siempre que cumplan los requisitos del apartado 4 del artículo 7, esto es: que su ejercicio no ponga en riesgo la sostenibilidad financiera del conjunto de la Hacienda municipal, de acuerdo con la legislación sobre estabilidad presupuestarias y sostenibilidad financiera; y que no se incurra en un supuesto de ejecución simultánea del mismo servicio público por otra administración pública. El cumplimiento de estos requisitos lo garantizan la administración concernida por la supuesta ejecución simultánea y por la administración que ejerce la tutela financiera de acuerdo con la legislación de estabilidad presupuestaria y sostenibilidad financiera. Tal y como antes señalaba el ejercicio de este tipo de competencias solo es posible por los grandes municipios. En definitiva la mayoría de las competencias propias, por delegación o al margen de las anteriores, solo pueden ser ejercidas por los grandes municipios que, por lo general, no están afectados por competencias de las diputaciones provinciales.

Así como el artículo 25 de la Ley se refiere al régimen jurídico de las competencias municipales, el artículo 26 está dedicado a establecer los servicios que los municipios deben prestar de manera obligatoria a los ciudadanos, teniendo en cuenta el parámetro de la población. Todos los servicios contemplados en el artículo 26 se corresponden a competencias municipales del artículo 25, pero en el artículo 26 no se agotan todas las competencias municipales del artículo 25 .

La Ley 27/2013 en su artículo 26 clasifica de manera indirecta a los municipios españoles al atribuir a los mismos, en función de la población, la exigencia de prestar diferentes servicios. Y, como veremos, dicha clasificación lleva implícita otra clasificación, la de municipios viables y municipios no viables que son coordinados por las diputaciones provinciales.

Todos los municipios sea cual sea su población tienen que prestar ocho servicios públicos ${ }^{25}$, los más elementales: alumbrado público, cementerio, recogida de residuos, limpieza viaria, abastecimiento domiciliario de agua potable, alcantarillado, acceso a los núcleos de población y pavimentación de vías públicas. Y, a partir de esos mínimos servicios, se asignan otros obligatorios a los municipios de más de 5.000 habitantes ${ }^{26}$, a los de más de 20.000 habitantes $^{27}$ y a los de más de 50.000 habitantes ${ }^{28}$. Además el título X de la Ley de Bases de Régimen Local, artículos 121 a 138, regula de manera singular la organización de los municipios de gran población, que se consideran las capitales de provincia, sea cual sea su población,

25 Alumbrado público; cementerio; recogida de residuos; limpieza viaria; abastecimiento domiciliario de agua potable; alcantarillado; acceso a los núcleos de población; y pavimentación de las vías públicas.

26 A las anteriores competencias se añaden las de: Parque público; biblioteca pública; y tratamiento de residuos.

27 A las anteriores competencias se añaden: Protección civil; evaluación e información de situaciones de necesidad social; atención inmediata a personas en situación de riesgo de exclusión social; prevención y extinción de incendios; instalaciones deportivas de uso público.

28 A las anteriores competencias se añade: Transporte urbano de viajeros; y medio ambiente urbano. 
capitales autonómicas o sedes de instituciones autonómicas, así como los municipios que superen los 75.000 habitantes, que presenten circunstancias especiales, a los municipios capitales de provincia cuya población sea superior a 175.000 habitantes y a los municipios cuya población supere los 250.000 habitantes.

En la Ley de Bases de Régimen Local se establecía un sistema de «asistencia» de las diputaciones a los municipios con la finalidad de prestación de los servicios públicos mínimos y las funciones de secretaría, recaudación, tesorería, intervención y control que corresponden a los cuerpos nacionales. Pues bien, de acuerdo con la Ley 27/2013 la asistencia se convierte en «coordinación» de la práctica totalidad de los servicios que están obligados a prestar todos los municipios con independencia de su población, excepto los cementerios, y que tengan menos de 20.000 habitantes. En el artículo 26.2 de la Ley 27/2013 se utiliza el término «coordinación» de modo eufemístico. En efecto, la que se denomina coordinación puede consistir en: prestación directa de los servicios en cuestión por la diputación; o bien mediante consorcios, mancomunidades y otras fórmulas. A las competencias de coordinación se añaden las competencias propias de las diputaciones provinciales reguladas en los artículos 36 y 37 de la Ley de Bases de Régimen Local, que no han sido modificadas, que afectan a los municipios de menos de 20.000 habitantes, al margen del plan provincial de cooperación a las obras y servicios de competencia municipal, que se suelen solapar con los planes de las comunidades autónomas.

Para que un municipio de menos de 20.000 habitantes pueda prestar los servicios antes señalados debe justificar, ante la diputación, que puede prestarlos con un coste efectivo menor que el derivado de la forma de gestión propuesta por la diputación provincial o entidad equivalente, pero en todo caso, para que la prestación se lleve a cabo por el municipio la diputación provincial deberá considerar acreditado el requisito en cuestión ${ }^{29}$.

No cabe duda de que la Ley 27/2013 es una ley que limita la autonomía municipal, pese a los preceptos de la misma declarados inconstitucionales y nulos por el Tribunal Constitucional, en unos casos por imperativo de la legislación de estabilidad presupuestaria y sostenibilidad financiera, pero la única justificación que puede invocarse es la de incrementar las competencias de las diputaciones provinciales, competencias que se proyectan sobre cerca del 90 por ciento de los municipios españoles ${ }^{30}$.

La conclusión que puede obtenerse (teniendo en consideración o sin tener en consideración la reforma de la Administración Local que ha llevado a cabo la Ley

29 La STC 111/2016, de 9 de junio declaró inconstitucional la atribución al Ministerio de Hacienda la competencia de elegir la forma en que deben prestarse los servicios por la diputación provincial.

30 No obstante algunos autores entienden que la Ley 23/2017 supone limitaciones a la autonomía de las provincias, ver J.M. SABATÉ I VIDAL, «El impacto de la Ley 27/2013, de 27 de diciembre, de racionalización y sostenibilidad de la Administración Local, en el régimen de las diputaciones provinciales y entes equivalentes, en Anuario de Gobierno Local, 2013, pp. 129 y ss. 
27/2013) respondiendo la pregunta que nos hacíamos al inicio de este epígrafe es que los municipios españoles pequeños, de menos de 20.000 habitantes, no pueden abordar la satisfacción de las necesidades más elementales de sus vecinos mediante la prestación de los servicios a que se hace referencia en el artículo 26 de la Ley de Bases de Régimen Local modificado por la Ley 27/2013 y, en consecuencia, la aplicación de los principios constitucionales de igualdad y solidaridad exigen que dichas necesidades se satisfagan por otras administraciones públicas. La cuestión es determinar cual es la solución organizativa más efectiva y eficiente.

\section{LA ORGANIZACIÓN ADMINISTRATIVA DEBE SUBORDINARSE A LAS NECESIDADES DE LOS CIUDADANOS}

La respuesta a las cuestiones que planteamos más atrás debe marginar posiciones ideológicas de poder y atender a las que pueden considerarse como soluciones más adecuadas para afrontar de manera eficaz y eficiente a las necesidades de los ciudadanos. La organización administrativa en las democracias avanzadas es preciso que se desprenda de prejuicios ideológicos y que se dote de flexibilidad, pues la organización debe tener en cuenta los cambios de todo orden que suceden en nuestras sociedades sin que ningún modelo organizativo se considere en el núcleo inconmovible del estado democrático, con la excepción de que quede preservada la división de poderes en el Estado.

Las provincias surgen con la encomiable finalidad de vertebrar España en el siglo XIX, de acuerdo con el principio centralista. Javier de Burgos, en la estela de la Constitución de Cádiz, es el artífice de una reforma del Estado que en 1833 inicia el desmantelamiento de una concepción medieval del gobierno del territorio español. Y durante más de un siglo la provincia en un Estado centralista como el español, particularmente tras la Guerra Civil, ha tenido las dos funciones de ente local y de división territorial para el cumplimiento de las actividades del Estado. Y muy particularmente como sistema de control de los municipios españoles. Lo cierto es que el diseño originario de la provincia como ente local no es en la actualidad reconocible, pues la función vertebradora del territorio se articula en la actualidad a través de técnicas más sofisticadas por el Estado y por las comunidades autónomas.

Cuando los constituyentes redactaron la Constitución de 1978, y pergeñaron un esbozo de lo que será posteriormente el Estado de las Autonomías, era difícilmente previsible el encaje en nuestro territorio de cuatro niveles político-administrativos: municipios (y otros entes locales de segundo grado), provincias, comunidades autónomas y estado central. Es más, puede afirmarse que el constituyente tuvo considerables dudas al redactar el artículo 141 del texto fundamental como acredita la circunstancia de que en el mismo se permitan diferentes posibilidades organizativas, alternativas y acumulativas. Además, a partir del 1 
de enero de 1986, con la entrada en vigor en España de los Tratados de las Comunidades Europeas, a las cuatro administraciones previstas en la Constitución se añadirá una quinta, la administración de la Unión Europea. Y la cuestión que debiera plantearse sería si es sostenible que sobre un mismo territorio operen cinco distintos conglomerados político-administrativos. En muchas ocasiones se hace referencia a los costes de esa maquinaria administrativa, en otros a su efectividad. A mi juicio el criterio que debe tenerse en cuenta es el de si dicho conglomerado es el adecuado para afrontar las necesidades de los ciudadanos, conglomerado que lejos de toda simplificación se ha ido incrementando tanto en el derecho interno español ${ }^{31}$ como en el derecho de la Unión Europea ${ }^{32}$.

El coste de los servicios públicos no debe ser nunca un parámetro decisivo para organizar la prestación de los mismos, pues de acuerdo con este criterio, el del coste, se podrían alcanzar soluciones simplistas como la de, por ejemplo, suprimir la sanidad pública como sucede en Estados Unidos, pues ello comportaría un ahorro significativo al Estado. Lo que debe ser determinante para mantener estructuras administrativas o servicios públicos es que sean necesarias para satisfacer las necesidades de los ciudadanos, particularmente cuando dichas necesidades no pueden ser atendidas por un mercado eficiente, lo que no obsta para exigir que tales estructuras y servicios sean eficaces y eficientes y, en esa medida, que sean lo menos gravosos para los ciudadanos.

Y del mismo modo puede sostenerse que ninguna estructura administrativa o política debe tener por finalidad contentar a políticos, castas, partidos y un largo etcétera. No debe permitirse que se patrimonialicen las instituciones poniéndolas al servicio de los que las sirven en vez de al servicio de los ciudadanos. Aunque, sin duda, esta es una de las patologías más frecuentes que se detectan a lo largo de la historia.

Las diputaciones provinciales han sido en la España democrática centros de poder regidos por criterios políticos en la mayoría de los casos contrarios a criterios técnicos dirigidos a satisfacer la necesidades de los ciudadanos. Centros de poder que, salvo excepciones, han estado guiados por intereses partidarios, en el mejor de los casos, y frecuentemente han sido instrumentos caciquiles desprovistos de

31 En el derecho interno español además de las variantes que se observan en lo relativo a la organización de las provincias como entes locales, la Ley de Bases de Régimen Local en su artículo 3.2 considera como entes locales las comarcas, las áreas metropolitanas y las mancomunidades de municipios. Además debe tenerse en cuenta el sector público institucional de los entes locales regulado en el artículo 85 de la LBRL que hace posible, para la gestión directa de los servicios públicos, la creación de organismos autónomos locales, entidades públicas empresariales locales y sociedades mercantiles locales, que se regirán por lo dispuesto en la Ley 40/2015, de Régimen Jurídico del Sector Público. Por otra parte para la gestión indirecta de los servicios públicos pueden utilizar el arsenal de técnicas de la Ley 9/2017, de 8 de noviembre, de Contratos del Sector Público, por la que se trasponen al ordenamiento jurídico español las Directivas del Parlamento Europeo y del Consejo 2014/23/UE y 2014/24/UE, de 26 de febrero de 2014.

32 En el derecho de la Unión Europea junto a la administración ordinaria que corresponde a la Comisión Europea se ha creado una auténtica costelación de agencias y organismos de la Unión. 
controles democráticos externos eficientes, pues los miembros de las diputaciones provinciales: no se eligen directamente por los ciudadanos de los municipios que agrupa; no luce en dichas corporaciones la separación elemental de los poderes legislativo y ejecutivo; se configuran como instituciones presidencialistas con menoscabo de sus órganos colegiados; y están prácticamente exentas de controles externos, al margen del Tribunal de Cuentas.

Aunque el análisis del gasto no puede considerarse decisivo para valorar las diputaciones, lo cierto es que la mayoría de los estudios coinciden en que de los más de 6.300 millones de gasto del conjunto de las diputaciones provinciales, de las 38 del régimen común, tan solo se destina un pequeño porcentaje a los servicios básicos, mientras que el porcentaje mayor de gasto se destina a la propia organización administrativa. Sin embargo, en la medida en que los servicios que prestan las diputaciones provinciales deben seguir prestándose, de lo que no cabe duda en la actualidad, no es evidente que la supresión de las diputaciones supusiera una reducción del gasto y una mayor eficacia y eficiencia. Si en una institución se aprecian disfunciones lo adecuado es afrontarlas, reformando la institución en cuestión. Y nada impide al legislador estatal afrontar una reforma profunda de las diputaciones que las convirtieran en corporaciones eficaces y eficientes, comenzando por la elección directa de su presidente y demás miembros del pleno de las mismas.

\section{EL FUTURO DE LAS DIPUTACIONES NO DEBIERA TRAZARSE DE MANERA AISLADA, SINO TENIENDO EN CUENTA LA ESTRUCTURA TERRITORIAL DEL ESTADO DE LAS AUTONOMÍAS. UNA PROPUESTA DE LEGE FERENDA}

En apartados anteriores hemos alcanzado la conclusión de que de acuerdo con nuestra Constitución, y teniendo en cuenta el precedente de la supresión de las diputaciones provinciales en las comunidades autónomas uniprovinciales, sería posible que las comunidades autónomas, en general, sin reforma constitucional sustituyeran a las diputaciones provinciales asumiendo sus funciones, pues podríamos considerar que las comunidades autónomas, a los efectos que nos ocupan, se pueden equiparar a las corporaciones representativas a que se refiere el artículo 141.2 de la Constitución. Esta, en definitiva, es la solución adoptada para las comunidades autónomas uniprovinciales, consideradas, a los efectos del artículo 141.2, como corporaciones representativas. De manera que la ley estatal podría proceder a que las diputaciones provinciales también fueran sustituidas por las comunidades autónomas pluriprovinciales.

La liquidación de las diputaciones provinciales y la asunción por las comunidades autónomas pluriprovinciales de las competencias que las mismas tienen en la legislación vigente comportaría un incremento considerable de competencias de las comunidades autónomas, y eliminaría el único freno administrativo a la 
expansión, sin controles, de estas últimas en el ámbito local. No debe olvidarse que los órganos de gobierno de las diputaciones provinciales se integran por miembros electos de los municipios que las integran, mientras que si se transfirieran las competencias de las diputaciones provinciales a las comunidades autónomas los municipios quedarían al margen del control de las decisiones tomadas en relación con los mismos, como sucede en las comunidades autónomas uniprovinciales en que han desaparecido las diputaciones provinciales y la provincia como ente local.

Se puede considerar, al margen de lo que después diré, que las diputaciones provinciales son un instrumento de control del expansionismo competencial autonómico, particularmente cuando el gobierno de las diputaciones corresponde a un partido o partidos políticos diferentes al que gobierna, o a los que gobiernan la comunidad autónoma. Desde esta perspectiva, y teniendo en cuenta los intereses de los ciudadanos, que existan diputaciones provinciales sería una garantía para la reducida autonomía municipal, porque resulta evidente que la concentración del poder es siempre negativa para los ciudadanos. Argumento al que debe añadirse que la supresión de las diputaciones provinciales y la atribución de sus funciones a las comunidades autónomas no conlleva de manera automática la corrección de las deficiencias que se han observado en las diputaciones provinciales.

Las decisiones que se adopten en el futuro en relación con las diputaciones provinciales no se debieran separar de una nueva estructuración del Estado en su conjunto que se reclama desde hace décadas. Si bien, las discrepancias entre los partidos políticos españoles sobre esta materia son considerables. Un indicio de estas discrepancias se ha puesto de manifiesto en la Comisión para la evaluación y modernización del Estado autonómico, creada recientemente en el Congreso de los Diputados para analizar el funcionamiento del Estado de las Autonomías ${ }^{33}$, en la que no participan los partidos nacionalistas vascos y catalanes, así como el partido Podemos. Y los partidos que se han incorporado a la Comisión (PP, PSOE y Ciudadanos) es notorio que mantienen posturas difícilmente conciliables en la materia.

Los partidos nacionalistas vascos ${ }^{34} \mathrm{y}$ catalanes se sitúan en posiciones que van desde la configuración de España como una confederación, como aspiración mínima, a la independencia de España de sus respectivos territorios. Por lo que se refiere a los partidos denominados constitucionalistas discrepan en cuestiones básicas, pues unos son partidarios de mayor autonomía mientras que otros

33 La primera sesión tuvo lugar el 15 de noviembre de 2017.

34 En un artículo titulado «Riesgo unilateral y solidaridad» firmado por el Lehendakari del País Vasco no solo se justifica el régimen fiscal vasco, que se corresponde al de un Estado confederal, sino que sostiene que «El sistema de Concierto se asienta sobre el principio de responsabilidad fiscal y financiera y lo realmente constructivo sería analizarlo como modelo de referencia que permita avanzar en un nuevo sistema descentralizado de financiación que resulte más eficiente, justo y solidario» . Ver «El País», de 4 de diciembre de 2017, pág. 11. 
postularían la recuperación por el Estado de algunas competencias significativas transferidas a las comunidades autónomas. Así, se da la paradoja de que todos postulan la reforma del Estado de las Autonomías, pero igualmente todos discrepan en la dirección de la reforma, lo que dificulta alcanzar acuerdos. Probablemente la única zona de entendimiento se encuentre en la necesidad de clarificar algunos aspectos del sistema de competencias, en particular el régimen jurídico de los diferentes tipos de competencias. Pero esta clarificación no es el objetivo principal de unos y otros. La cuestión podría resumirse diciendo que unos quieren más peso del Estado, mientras que otros quieren más peso de las comunidades autónomas hasta convertir el Estado de las Autonomías en una confederación, en definitiva el retorno a la estructura del Estado en tiempos de los Austrias.

La liquidación de las diputaciones provinciales se inscribe en la línea de los que pretenden una deriva del Estado de las Autonomías hacia un Estado confederal, en cuya concepción este tipo de instituciones intermedias, que no están intervenidas por las comunidades autónomas, son un obstáculo. Las comunidades autónomas en la actualidad no son solo uno de los niveles de la estructura administrativa del Estado de las Autonomías sino que se han ido construyendo como Estados federados integrados por municipios ${ }^{35}$. Los municipios no son un escalón independiente y autónomo de administración sino que son parte integrante de la Comunidad Autónoma. La Constitución permitía otras interpretaciones, pero el caso es que la anterior ha sido validada por las leyes y por el Tribunal Constitucional.

Si lo que se pretendiera fuera salvaguardar la limitada autonomía de los municipios y, a su vez, afrontar el minifundismo municipal son posibles opciones diferentes a la de fortalecer las diputaciones provinciales o a transferir sus competencias a las comunidades autónomas. Veamos. La planta municipal vigente está integrada, de una parte por 396 municipios de más de 20.000 habitantes que suman un total de más de 31 millones de habitantes que podrían quedar como están, en la medida en que, salvo excepciones, no reciben la prestación de servicios por las diputaciones provinciales y, por otra parte, existen unos $7.719^{36}$ municipios con poblaciones que van desde cifras inferiores a 100 habitantes a los

35 Sirva como ejemplo el artículo 2.3 del Estatuto de Autonomía de Cataluña que dice:» Los municipios, las veguerías, las comarcas y los demás entes locales que las leyes determinen, también integran el sistema institucional de la Generalitat, como entes en los que ésta se organiza territorialmente, sin perjuicio de su autonomía.» Esta deriva y la pretensión eufemística de que las Comunidades Autónomas mediante los nuevos órganos de participación local garantizarían mejor la autonomía local puede verse, por ejemplo, T. FONT Y LLOVET Y M. VILALTA REIXACH, «Los diferentes modelos de participación local en los nuevos Estatutos de Autonomía», Revista d'Estudis Autonòmics i Federals, no 8, abril, 2009, pp. 192 y ss. Mayor interés sobre el tema tiene el trabajo de A. EMBID IRUJO, «Informe general sobre el gobierno local en 2010», Anuario Aragonés del Gobierno Local 2010, Zaragoza, 2011, pp. 11 y ss. También tiene interés el trabajo de A. IGLESIAS MARTÍN, Autonomía municipal, descentralización política e integración europea de las entidades locales, Ariel Derecho, Barcelona, 2002.

36 De menos de 100 vecinos, unos 1.041 municipios, de 100 a 500 vecinos, unos 2759 municipios, de 500 a 1000 vecinos, unos 1.062 municipios, de 1.000 a 5.000 vecinos unos 1937 municipios, de 5.000 a 10.000 vecinos, unos 569 municipios y de 10.000 a 20.000 vecinos unos 335 municipios. 
de menos de 20.000 habitantes. Estos 7.719 municipios se podrían reorganizar creando nuevas entidades municipales que podrían llamarse, por ejemplo, comarcas municipales ${ }^{37}$, u otra denominación, que agruparían un número de municipios con población suficiente para poder satisfacer la práctica totalidad de los servicios previstos para los municipios de más de 20.000 vecinos. De manera que podrían reducirse los 7.719 municipios (de régimen común o de régimen especial) de menos de 20.000 habitantes a unas 750 comarcas municipales, con supresión de las provincias como ente local. Las cifras antes señaladas deben tomarse como una mera aproximación. El caso es que la suma de los municipios autosuficientes y de los municipios comarcalizados estaría en torno a los 1.146, en vez de los 8.115 actuales.

Al margen de la reducción del número de municipios, que no es un tema menor, las comarcas serían entidades locales en que estarían representados todos los vecinos de la comarca en cuestión. Los núcleos urbanos, antes municipios, estarían representados en los órganos de gobierno de las comarcas municipales, de manera que sus peculiaridades quedaran garantizadas. En este esquema sería igualmente necesario establecer organizaciones sin personalidad jurídica, del tipo de conferencias de las reguladas en el título III «Relaciones interadministrativas» de la Ley 40/2015 de Régimen Jurídico del sector Público, en que estarían representados los municipios autosuficientes y las comarcas municipales con la finalidad de establecer con el Estado y la correspondiente comunidad autónoma una coordinación eficaz y eficiente con las políticas autonómicas y estatales y, en especial, para establecer las reglas relativas a la financiación de municipios y comarcas municipales

A esta reforma debiera añadirse otra consistente en la delegación por el Estado y las comunidades autónomas de la ejecución de competencias en los municipios autosuficientes y en las comarcas. Y, asimismo, debiera incrementarse el gasto municipal equiparándolo en su conjunto al de las comunidades autónomas, asemejando la distribución del gasto al de los Estados federales. En definitiva se trataría, en una reforma futura de nuestro Estado de la Autonomías, de llevar a cabo la segunda descentralización ${ }^{38}$, olvidada en España como consecuencia de la presión que sobre el Estado han ejercido las comunidades autónomas que pretenden conducir el Estado de las Autonomías a un modelo confederal con reducción del poder del Estado central y de los municipios.

La reforma que se postula, sin embargo, no haría sino afrontar una de las deficiencias de nuestra organización administrativa que sigue anclada en las

37 Las denomino e este modo para diferenciarlas de las comarcas de la Ley de Bases de Régimen Local, dado que las comarcas municipales serían ente locales que sustituirían a los municipios que agrupan se convertirán en entes locales de segundo grado de los entes locales principales que serían las comarcas municipales.

38 Puede verse el libro colectivo E. LINDE y otros, La segunda descentralización. El pacto local, Colex, Madrid, 2005. 
técnicas de pasado siglo inadaptadas a los retos de nuestro mundo globalizado. La coordinación entre las diferentes administraciones públicas, la colaboración entre las administraciones públicas y la sociedad, y la incorporación de nuevas organizaciones y técnicas, desligadas de las viejas concepciones territoriales están por ver la luz. Ese debiera haber sido el objeto de la Ley 40/2015 de Régimen Jurídico del Sector Público que no ha hecho otra cosa que reiterar lo que ya existía intentando dar la apariencia de que se producían innovaciones de calado en nuestro ordenamiento jurídico. Pero, lamentablemente no ha sido así. Habrá que seguir esperando que los poderes públicos conecten con los problemas y retos actuales y se atrevan a afrontarlos. Entre tanto seguiremos recibiendo el Derecho de la Unión Europea, origen de la moderada modernización de nuestras administraciones públicas.

\section{$* * *$}

TITLE: The provincial councils and their uncertain future

ABstract: Provincial councils are currently indispensable, given the Spanish municipal smallholding. However nothing prevents the deputies are extinguished and their functions are transferred to other representative corporations. In the work the thesis is sustained that it is possible the suppression of the deputations and their substitution by the autonomous communities. But it is also possible to substitute provincial councils for local entities that put an end to municipal smallholding. The first alternative would involve a considerable increase in the competences of the autonomous communities, with a reduction in local autonomy. On the contrary, the second alternative would put an end to municipal smallholding and preserve local autonomy more effectively. Finally, it is considered that the future of the provincial councils should not be traced independently of the new configuration of the State of the Autonomous Regions, since the choice of one of the two pointed solutions, or others, depends on this new configuration.

RESUMEN: Las diputaciones provinciales son en la actualidad indispensables, habida cuenta del minifundismo municipal español. No obstante nada impide que las diputaciones se extingan y sus funciones se pasen a desempeñar por otras corporaciones representativas. En el trabajo se sostiene la tesis de que resulta posible la supresión de las diputaciones y su sustitución por las comunidades autónomas. Pero es igualmente posible la sustitución de las diputaciones provinciales por entes locales que pongan fin al minifundismo municipal. La primera alternativa supondría el incremento considerable de las competencias de las comunidades autónomas con merma de la autonomía local. Por el contrario, la segunda alternativa pondría fin al minifundismo municipal y preservaría de manera más efectiva la autonomía local. Finalmente se considera que el futuro de las diputaciones provinciales no debe trazarse de manera independiente de la nueva configuración del Estado de las Autonomías, pues la elección de una de las dos soluciones apuntadas, o de otras, depende de dicha nueva configuración.

KEY WORDS: Provincial councils, autonomous communities, municipal smallholding, local autonomy.

Palabras Clave: Diputaciones provinciales, comunidades autónomas, minifundismo municipal, autonomía local.

FECHA DE RECEPCIÓN: 10.09.2017

Fecha de ACEPTACión: 01.02.2018 
